\title{
Addressing Knowledge Support Services as Part of a Living Lab Environment
}

\author{
Albertus A. K. Buitendag, Jacobus S. van der Walt, \\ Tumelo Malebane, and Lizette de Jager, \\ Tshwane University of Technology, Pretoria, \\ Tshwane, South Africa
}

buitendagAAK@tut.ac.za vanderwaltJS@tut.ac.za malebaneT@tut.ac.za dejagerL@tut.ac.za

\begin{abstract}
The concept and implementation of Living Labs are gaining momentum in Southern Africa. Within a Living Lab environment, information and knowledge dissemination can take on many forms and are cardinal to its successful operation in the creation of innovative solutions. This paper presents an expanded Living Lab framework which utilizes different services represented collectively as knowledge support services in order to fulfill and enable various knowledge oriented activities. These activities include information acquisition, learning and knowledge sharing. The activities are facilitated by the implementation of services. Some of these envisioned services include a question and answer service, a knowledge interchange service and a reverse knowledge brokerage service, are described and conceptually presented in this paper. The services are built on the utilization of existing tools, current services and emergent semantic technologies.
\end{abstract}

Keywords: Knowledge acquisition, Knowledge brokerage, Knowledge sharing, Knowledge support, Living Labs.

\section{Introduction}

This paper continues research presented in 2009 where van der Walt et al. (2009) modeled a Living Lab (LL) around a factory concept. In this paper we provide new insights and thoughts on the knowledge support activities which we envision as cardinal in the successful functioning of a Living Lab. The presented LL factory framework is based on research pertaining to the creation of a Living Lab for emergent farmers, which would also be applicable in other domains such as education, manufacturing, finance etc. This aims at providing a broader more detailed description of the Living Lab factory framework based on emergent technologies, current LL cases, and a literature review.

Material published as part of this publication, either on-line or in print, is copyrighted by the Informing Science Institute. Permission to make digital or paper copy of part or all of these works for personal or classroom use is granted without fee provided that the copies are not made or distributed for profit or commercial advantage AND that copies 1) bear this notice in full and 2) give the full citation on the first page. It is permissible to abstract these works so long as credit is given. To copy in all other cases or to republish or to post on a server or to redistribute to lists requires specific permission and payment of a fee. Contact Publisher@InformingScience.org to request redistribution permission.
The concept of Living Labs and "Living Labbing" which we define as: "The active participation by the community of practice $(\mathrm{CoP})$ and other stakeholders in some or all living lab activities, which may also include in sharing the reward" is a fairly new phenomenon. The LL concept is based on driving innovation and user-centric development (lltoolbox.eu, 2009). This approach encourages the need to place producers, con- 
sumers and users of products and services at the centre of their development. This plays an essential role in ensuring that products and services are developed for the right market, utilizing the best optimal strategies. New products and services play different roles in users' day-to-day lives, and as such, care must be taken in providing relevant products which meet the needs of the consumers and users. The only way to meet the real needs of the consumers is by allowing them to be part of the process that creates them (Bergvall-Kåreborn et al., 2009).

Living Labs encourage innovation practices as well as the exchange of new ideas and information, which promote the concepts of innovation and co-creation (Kusiak 2007:866). LLs bring together different stakeholders, both from the public and private sectors. They come together with a common goal of creating relevant products which will be accepted by the market. In many cases the created products are ICT enabled tools and services (such as mobile services) adapted or created from existing mobile platforms (e.g. MXit, Mobi, J2ME) providing specialized development services (RLabs.org, 2012).

According to Følstad (2008), the co-creation concept includes for example, to investigate the context in which ICT is used (i.e. context research), to discover new uses and service opportunities for ICT, to involve users as co-creators, to evaluate/validate new ICT solutions with users, and to conduct technical testing of ICT products and/or services in an everyday (user) context. We believe that knowledge sharing, collaboration and co-creation are essential activities within a Living Lab environment. They play an important role in ensuring the success of the initiative. Good communication techniques as well as knowledge sharing tools are needed within the Living Lab.

In a study conducted by Buitendag (2011) it was found that emergent farmers in South Africa are generally faced with constant changes and numerous challenges in conducting their agricultural operations. Some of the challenges highlighted include: 1) Major skill gaps in various facets of farming which are the result of inadequate information dissemination, access to the correct information and subsequent knowledge support by agricultural extension officers; and 2) a lack of proper support structures and tools for agricultural extension officers to facilitate their daily operations

Farmers which include emergent farmers are required to react speedily to changes and challenges to be able to compete in the current global economy. For the majority of farmers, this adds a lot of complexity to their business, because they are frequently not close enough to their customers to understand these changes and to proactively deal with it. This is even truer of the particular case of emergent farmers in Southern Africa (Thompson, van der Walt, \& Buitendag, 2011).

We believe that the application of a Living Lab approach can assist farmers to obtain access to commercial markets, and provide the farmers with a better opportunity to actively contribute to the agricultural value chain.

\section{Living Labs Defined - An Activity Perspective}

Organizations aim to provide cutting edge and innovative products and services to their consumers. However, most ICT-innovations fail to recognize the dynamic and implicit day-to-day user experiences, resulting in project failure as argued by Frissen and van Lieshout (in Schuurman, Moor \& Marez, 2010). Furthermore, innovative new ways of testing new products and services before they reach the market are needed (Leon, Eriksson, Balasubramaniam \& Donnelly, 2006). As a result there is a decline in the success rate of services and products that reach the market. According to Chen (2011) this kind of decline can be attributed to how satisfied a user is with a product, rather than the actual functional performance of the product itself. With that being said, the user satisfaction with the product can be a direct result of how comfortable or familiar the user is with a given product or service. The way people interact with products, services and applications in their daily lives should be seen and treated as the root of innovation (Bergvall-Kåreborn 
et al., 2009). Over the years, there has been an increased focus on developing mechanisms that put the user at the center of product development. Living Labs (LL) have emerged as a result of such efforts.

LLiSA (2011) defines Living Labs as: "Systemic initiatives, which focus on creating multistakeholder collaboration in different stages of the research, development and innovation (RDI) process”. The concept refers to a research and development methodology where innovation such as services, products and application enhancements are created and validated in collaborative, multi-contextual empirical real-world settings. In the words of Cunningham, Herselman, and Cunningham (2011): Living Labs are environments, a methodology or an approach which caters for user-driven open innovation within real-life rural and urban settings/communities, where users can collaborate with multiple committed stakeholders in one or more locations, to become cocreators or co-designers of innovative ideas, processes or products within multidisciplinary environments. Successful deployments can result in improved processes or service delivery, new business models, products or services, and can be replicated to improve overall quality of life and wider socio-economic impact in participating and other communities”.

In Living Labs, users or citizens are seen as a source of new innovation, as co-creation or application of ICTs or ICT-enabled services. Living Labs are platforms for exploring these opportunities in various areas (Coetzee \& Du Toit, 2011; Følstad 2008).

The most important aspect of any living lab project is that it must be implemented in a real-world context driven by and for its intended community of practice (CoP) (Bergvall-Kareborn et al., 2009).

Figure 1 depicts some of the envisaged LL activities; which also highlights some of the LL users, which are seen as various entities, each of which could potentially benefit from the different outcomes of each of the activities performed.

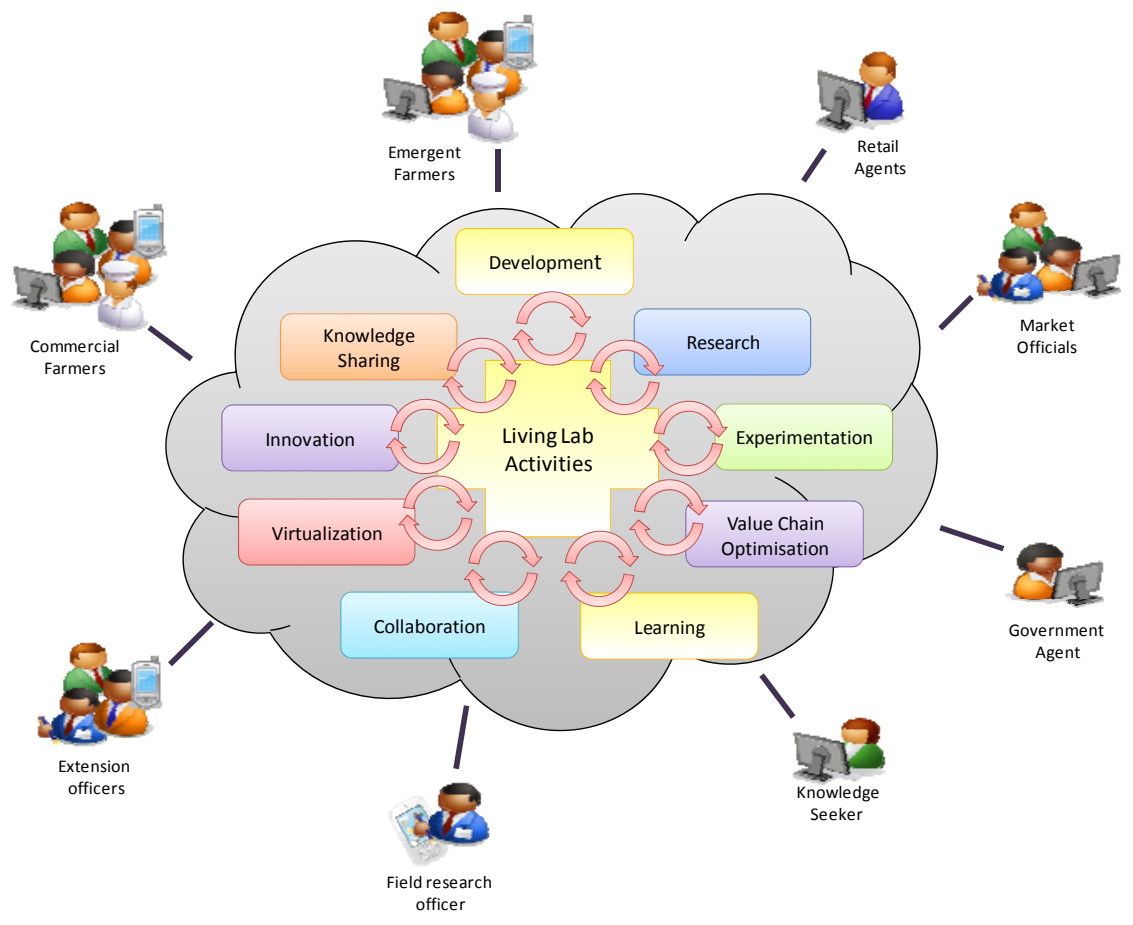

Figure 1 - Living Lab Activities and Users 
Leven \& Holmstrom (in Schuurman et al., 2010) identified the researcher, developer and user as the main stakeholders (roles) in a living lab, and within the context of an agricultural LL the roles of each of the stakeholders could be described as follows:

- The focus of the researcher which could include extension officers, as well as agricultural researchers from governmental agencies, is to bring about new knowledge.

- The developers which could include existing commercial farmers, as well as other agricultural entities or the LL (CoP), themselves aim to produce the new service or product for a particular consumer, or to address some LL requirement, e.g. a new tool, new service or even new knowledge.

- The users will be the consumers of the new service or product being developed, which from a LL perspective could also include the current LL CoP.

What differentiates the LL approach to other generic organizations, resides in the fact that LLs are driven, motivated and evolve around CoPs. Where there is a strong focus on profit for sustainability in normal organizations, LL's on the other hand (with specific reference to Southern Africa) are often centered on innovation, co-creation, co-existence and community advancement (Coetzee \& Du Toit, 2011; Cunningham, Herselman, \& Cunningham 2011; Følstad 2008). This is often the case in rural communities as is highlighted in the next section.

The reward of "Living Labbing", often encapsulate more than just the tangible or financial reward but promote the uniquely African concept and philosophy of 'Ubuntu' a Zulu or Sotho aphorism which implies that "A person is a person through other persons". Cilliers (2008) explains that it is impossible to do the concept justice due to the richness of it within the African context, and points out that it also underpins the concept of an open society. The concept of an open society is often linked to LL's which are often referred to as open living labs (c.f., openlivinglabs.eu 2012)

\section{Living Labs in South Africa}

There has been a global boom in the creation and advancement of Living Labs since the initiative was started by the European government, with more than 300 established LL's in Europe and 13 in Southern Africa alone Equally, Living Labs are used in various ways across the different parts of the world; and they are normally created and maintained through a standard setting body, depending on the country the Living Lab initiative resides in. South Africa has such body called Living Labs in South Africa (LLiSA).

LLiSA, launched in 2009, is an initiative aimed at creating a community and network of Living Lab practitioners in the Southern African region (LLiSA, 2011). The aim is to advance and support the open user-centric innovation and Living Labs in South Africa. This initiative is supported and coordinated by three parties, namely COFISA (http://www.dst.gov.za/links/cofisa), SAFIPA (http://safipa.com/) and the Meraka Institute (http://www.csir.co.za/meraka/). LLiSA aims to create a multidisciplinary platform where different stakeholders can collaborate, where the user is driving the innovation in real life contexts.

Some of the LLiSA development goals and objectives are listed below i.e.

- Building coordinated networks of users,

- Facilitating learning,

- Encouraging collaboration between various stakeholders,

- Disseminating and create knowledge, and knowledge transfer between various entities,

- Creating platforms for research implementing different technologies and models, 
- Providing evaluation, feedback and reporting services on ongoing innovations and initiatives.

The above mentioned LLiSA goals clearly indicate the direction and objective of the project, with a strong focus on developing and maturing the concept of Living Labs. This will ultimately yield a steady framework of Living Labs initiated and used by different stakeholders across the country, and ripping the benefits of user-centric development and innovation.

The researchers believe that each of the LLiSA goals and objectives could easily be presented as services in the LL environment, utilizing existing services and tools as well as possible services from the Cloud. These services could incorporate Web 2.0 and Web 3.0 technologies through mash-ups. Our proposed LL framework which will be presented at a later stage in this article incorporates a factory approach in the grouping of LL members, services and activities.

Figure 2 provides an overview of three of the most successful living labs in South Africa. It highlights the successes as well as the approach followed in each of the LL's
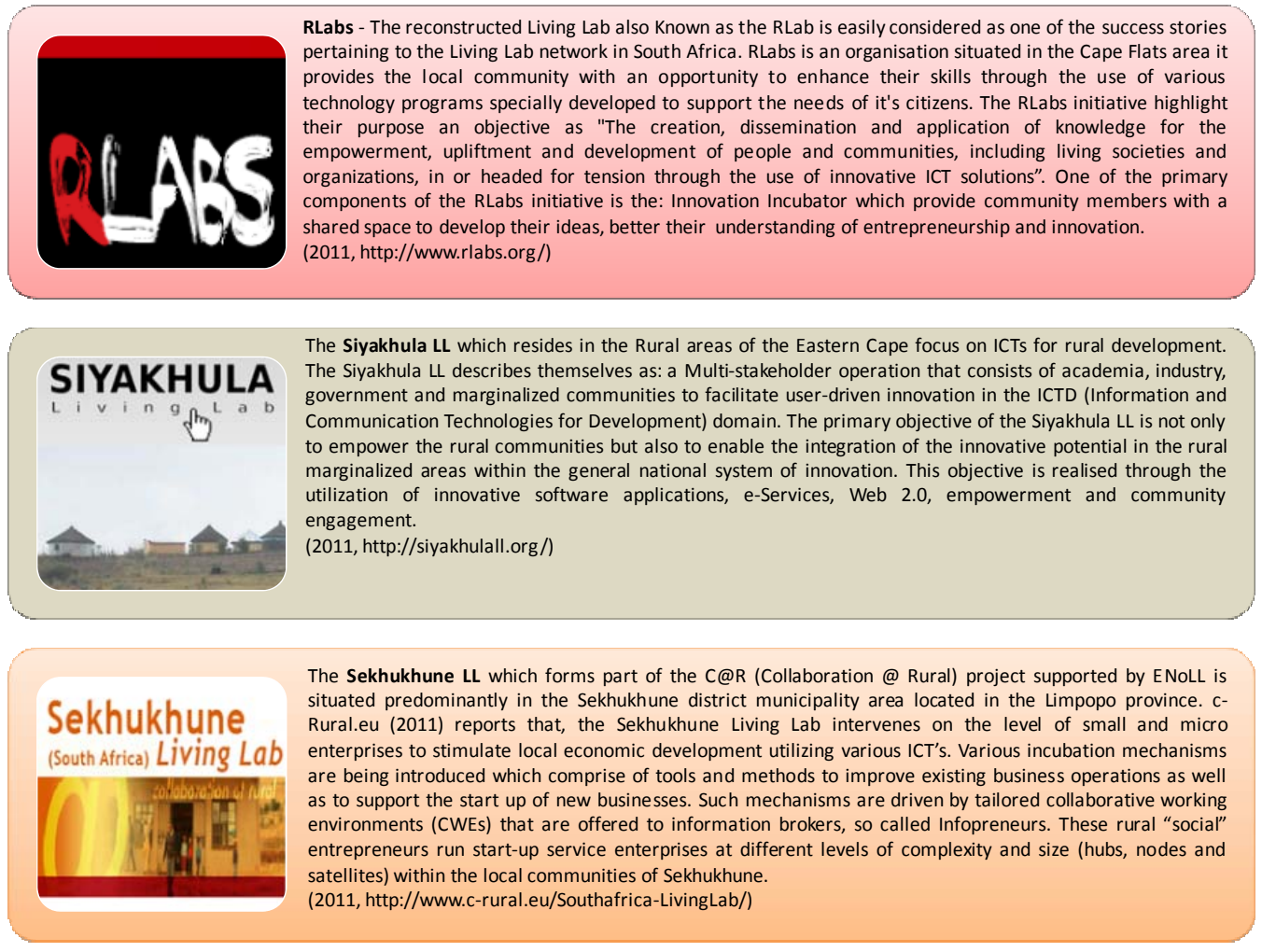

Figure 2 - Successful LL examples in South Africa

The Living Lab initiatives are mostly situated in rural regions and aim to provide new services that will improve the citizen's way of life through the quality of services they receive and the products they are exposed to. We are of the opinion that the inclusion of various services as part of a LL will not only increase the user engagement but will also attain and promote collaboration. Services for LL members which include emergent farmers are seen as key deliverables.

\section{Emergent Farmers, Extension officers, and their Challenges}

The South African agricultural landscape is unique in various aspects relating to factors such as the government's attempt to address issues such as land reform and sustainable agriculture. The South African National Department of Agriculture NDA (2006) distinguishes between 3 different 
types of farmers, i.e., 1) commercial farmers; 2) emergent farmers; and 3) subsistence farmers. Another subsection of commercial farmers is emergent or developing farmers, defined as farmers who are mainly dependent on state and semi- state organizations for land, support of various natures as well as finance (NDA, 2006)

In South Africa most agricultural departments and support structures provide extension and information services of a general nature to all farmers, including emergent farmers. The most common activities of extension officers include the dissemination of information and knowledge on farming management, technical issues as well as financial issues. Extension officers are key enablers in the provision of knowledge and alternative methods to persuade clients (which include emergent farmers) to apply new or bettered practices out of their own free will. The Free State provincial Department of Agriculture (2010) lists and motivates the following services rendered by their department, by explaining that:

- Commercial farmers are in need of more advice on management issues and alternative products. Their level of expertise varies and therefore their needs are also divergent. For instance, they need farming management advice, technical advice and financial advice.

- Emerging farmers need training and advice on various issues, such as farming management, technical and financial issues.

Grounded theory research conducted by Buitendag (2011) presented Figure 3 to highlight the issues and obstacles of emergent farmers, as well as extension officers' face within the South African context.

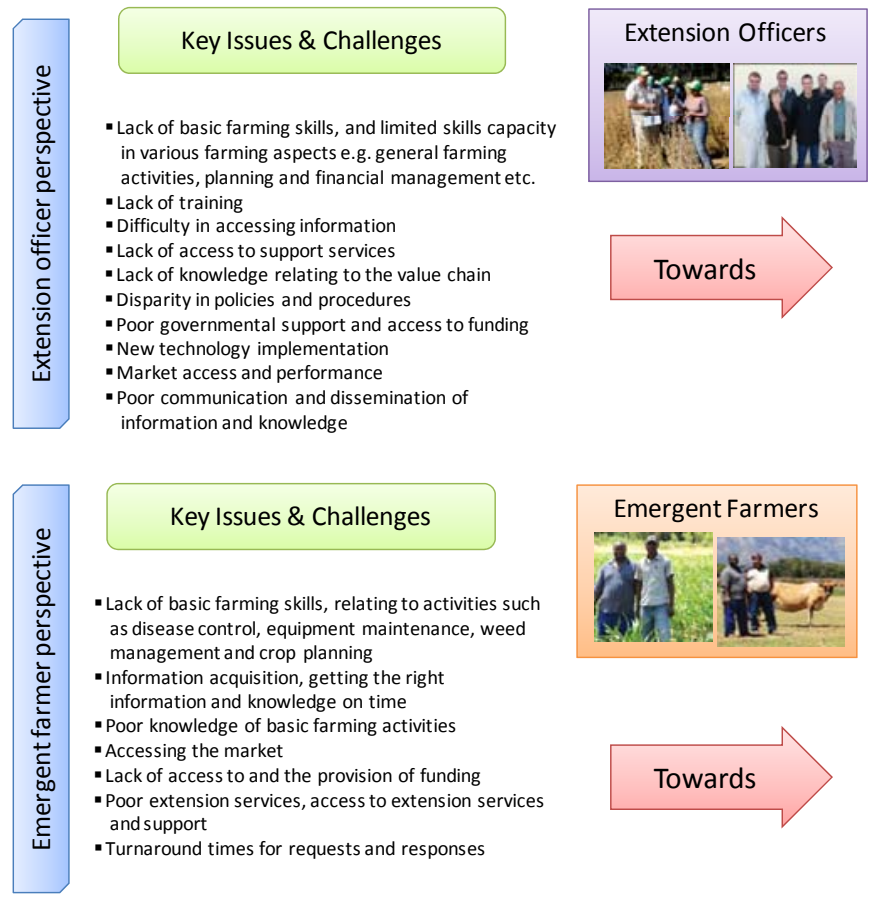

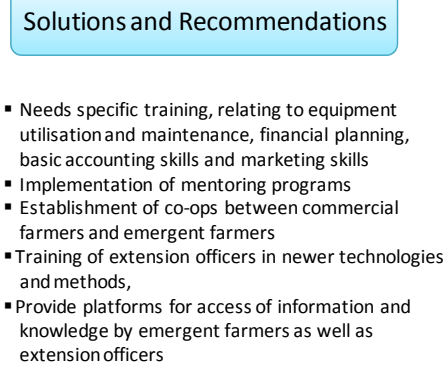

Solutions and Recommendations

- More training and workshops

- Better help from extension officers in making the right decisions i.e. provide extension officers with

the right know how.

- Provide the correct extension officer with the

correct knowledge and skills

- Provide better technical support, as well as post

production support and follow-ups.

- Provide for better dissemination of information and

knowledge.

- Establish co-ops between champions emergent farmers and existing commercial farmers.

Figure 3 - Perspectives and highlights on emergent farming issues

Figure 3 depicts the issues, suggested approaches and recommendations as possible solutions from the views and perspectives of the emergent farmers themselves as well as the extension officers. The figure also highlights the fact that there is a definite need for better access to real-time information and knowledge by emergent farmers via the extension officers. 


\section{Presenting the Extended Living Lab Framework}

We believe that many of the issues and challenges faced by emergent farmers as well as extension officers could be addressed within a Living Lab environment. The following adapted LL framework originally presented in 2009 by van der Walt et al. (2009) is modeled around the creation and utilization of virtual factories. The extended framework is depicted in Figure 4.

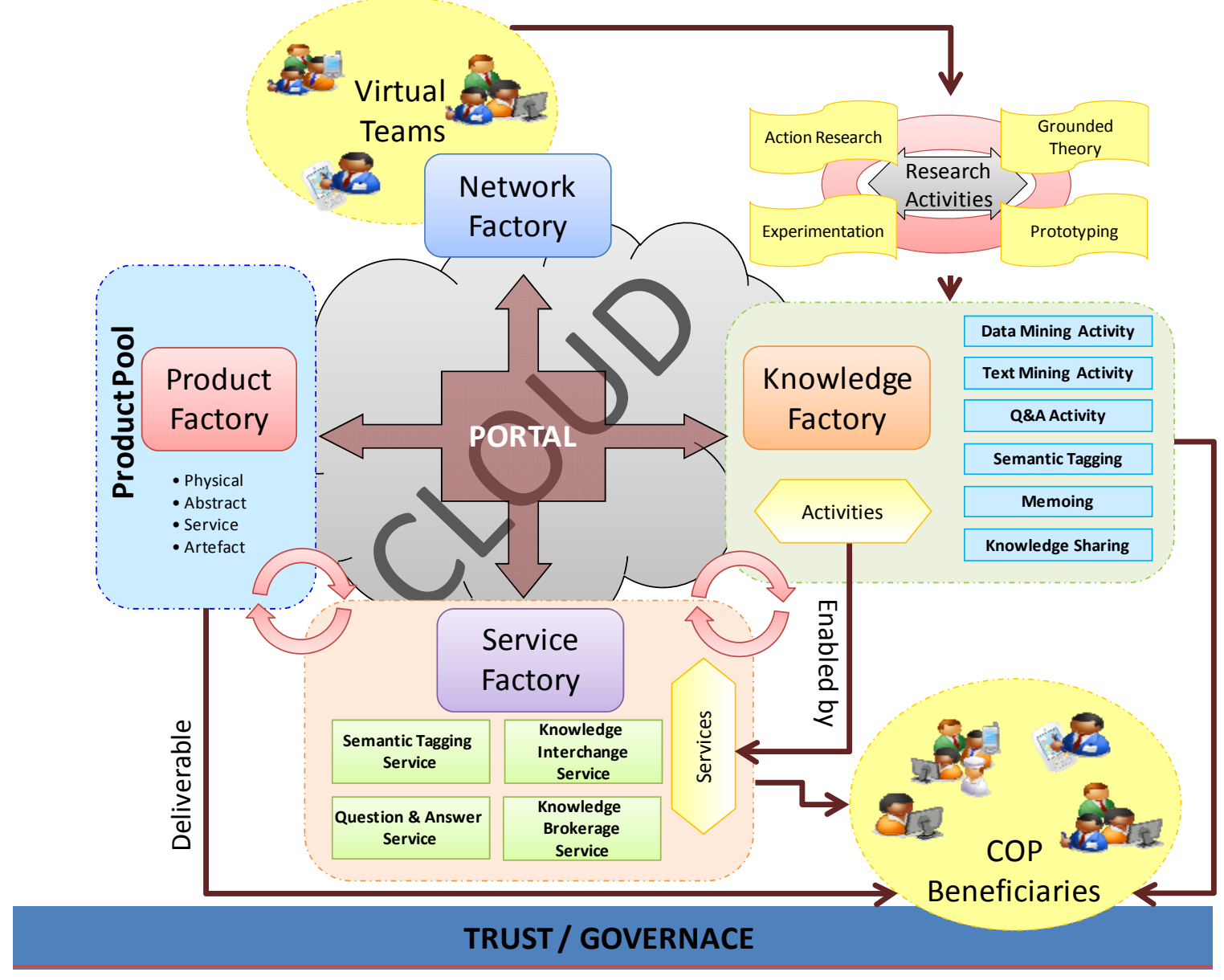

Figure 4 - Living Lab Factory Framework

Each of the virtual factories is modeled around the logical groupings of similar functions and activities. The virtual factories are partially based on the concept of a real life factory with some similarities to the factory design pattern as well. The logical model of the factory design pattern is based on the idea that products are created in a factory in which a client focuses on its discrete role in the application without concerning itself with the details of how the product is created. (Purdy, 2002) With reference to our framework, the client could either be a human client such as a research officer or a software client requesting the invocation of other software services.

The idea and concept of a software factory have also been researched (c.f., Greenfield \& Short, 2003; Lenz, 2008; Valderrama, Cruz, \& Valderrama 2011). Lenz (2008) explains that, a software factory comprises of a schema which is an instance of a software factory template and that the schema is a description of how to implement the products that can be produced with the software factory. Lenz (2008) explains that "The Software Architects define and implement a collection of core assets that make up the common and variable features of a product line and provide exten- 
sion points to add additional functionality. The Software Factory Schema describes the assets, artifacts, and activities necessary to produce the applications in scope of the Factory.”

Valderrama et al. (2011) describes a software factory as an organizational structure specialized in the production of materials based on software components according to user and end-user specifications and requirements. Within a software factory the same manufacturing techniques and principles apply, similar to domain engineering and software development. They further explain that the processes intend to mimic the benefits of traditional product manufacturing.

Our framework incorporates various factories such as the following, to accomplish various tasks and objectives, based on the logical groupings of processes and activities:

1. Social networking factory (NF) for profiling and registration of community members.

2. Tools/product (PF) factory for the creation of tools and methodologies for the LL.

3. Service factory (SF) for the creation of all the services needed by the community. The services may include physical and non-physical services such as web services. This article expands on some of the suggested services and provides some models and recommendations relating to current technologies available, that could be implemented; as well as designs for newer services to aid knowledge discovery, support and dissemination.

4. Knowledge factory (KF) which creates a dynamic set of knowledge objects implementing a question and answer extrapolation tool (QAET). The QAET is built upon the utilization of questions in order to create reusable knowledge objects. The primary purpose of the QAET is in the management of user requests, and the formation of knowledge objects stored in the knowledge object repository (KOR). We define a knowledge object (KO) as any artifact that could be implemented by a knowledge seeker in order to learn or expand the user's current knowledge regarding the specific search topic. KOs can take on a variety of formats, ranging from digital media to WEB 2.0 mashed objects. All KOs utilized are stored and managed in a knowledge object repository, which is in essence a semantic web cataloguing system. A Living Lab can support knowledge transfer (important know how) and improve various practices - rooted in innovation, education, research and technology use. Innovation can improve food security through wealth creation and business growth. A LL is supported by a set of tools to create an innovation factory.

In other words: The NF aims at establishing groups and virtual teams of people based on the social networking concept. The various virtual teams will often participate or initiate different research activities, for example action research or grounded theory research. The research activities will sometimes result in the generation of new knowledge such as the identification of new product or service requirements. The data, information and knowledge generated as part of amongst others, the research process classified and categorized to for future use within the KF. The KF uses standard ontologies and RDFs in the classification of all knowledge resources. Often new services will be designed based on the knowledge generated as part of the KF. The services are rendered and created to form part of the SF. The development and deployment processes of the service could initiate new research activities involving some or all of the virtual team members. Various activities of the KF are enabled through the utilization of services previously designed and developed in the SF. The SF and KF activities often result not only in the creation of services, but could also lead to the creation of artifacts.

The LL in this study has been seen as an incubator and test bed for development of market cooperation's and other community of practice driven collaborations such as agricultural community development, based on systems thinking. 
The tools and PF, as well as the SF utilize knowledge objects. The proposed knowledge discovery and support services also aid in the classification of knowledge obtained through some of the LL activities. Some of the envisioned activities include research, experimentation, innovation and artifact development. Through the research activities new knowledge is derived, which is processed as part of the knowledge factory. The created knowledge objects are categorized using standards which are stored and made available for future referencing and use. The knowledge objects are also part of the LL domain which could be available for use by other LL's and communities. In some instances the knowledge objects could be sold to generate income.

Innovation in today's day and age is of vital importance to any organization. With the current economic climate in a crisis, organizations' need to concentrate on increasing their efficiency to the maximum, with the least amount of effort and costs involved. As a possible partial solution to their problems, cloud computing opens doors for the application of technology to provide solutions to some of the technology requirements of a LL.

Many definitions of what cloud computing is, exist. Nabil (2010) defines cloud computing as "clusters of distributed computers (largely vast data centers and server farms) which provide ondemand resources and services over a networked medium (usually the internet)". It is a highly scalable form of computing that provides the use of virtualized resources over a network (internet) and makes use of virtual machine technology (Arshad, Townend \& Xu, 2011; Tuncay, 2010). This new wave of computing allows organizations to use software and processing power without having to invest in the infrastructure required to bring about those resources. According to Dorey and Leite (2011) cost reduction, improved provisioning, pay-for-use model and access to scarce resources are the main benefits of this phenomenon.

We believe that many of the envisioned activities and software requirements could be facilitated from services available in the cloud, which is particularly favorable for dispersed environments such as LLs. We do however, take cognizance of the fact that it will be impossible to find a complete solution for a LL in the cloud due to current cloud limitations, but the implementation thereof holds promise. Certain services needed, would still require the traditional approach to its development.

\section{Living Lab 'Portal' and Knowledge Support Services}

All the factories are interconnected and enabled via a portal which could be implemented quickly through the use of mash-up technology. The power of mash-ups can allow powerful and very functional Web applications to be created within a short period of time, to service the Living Lab and its members. This kind of development does not require the services of highly skilled developers. By nature mash-ups are highly customizable and can be built to suit the individual needs of the Living Lab, which will allow the technology to be accessible via various social platforms such as Facebook and Google+. Harnessing the tools, networking and social aspects available from these technologies, will in turn encourage knowledge creation and sharing, as all the necessary information and facilities are available. Tag clouds can be implemented within these web applications and they can help users get a quick view of the most important topics in the discussion. This will allow users to have a common graphical view of everyone else's ideas and how popular they are in terms of their discussions.

Logging on to a traditional portal or e-learning centered portal places the user on a platform towards an overabundant source of knowledge and information. Most users accessing a portal will access the portal to facilitate information acquisition in the creation of solutions (that is, knowledge creation) for their problem. Within the Living Lab portal environment information acquisition may be facilitated by the following three distinct sources: 
1) The current user group (CoP) including other users and domain experts (exchanging information through social media channels such as Wikis, Blogs and Facebook).

2) The knowledge/information system as part of the KF itself (through research activities such as grounded theory, action research and experimentation as well as other normal searches, data mining and data transformation).

3) External expert knowledge supplied either on a voluntary base or obtained through a brokerage where knowledge and expertise are bought from experts through reversed auctions - in cases where relevant knowledge cannot be found by researchers.

Information acquisition is the first step in the problem solving process. As information is acquired to aid in the individual or group's problem solving processes, new knowledge is evidently created. The knowledge created is generally specific in nature, and applicable to the user's problem solving needs.

The process of transforming the information into knowledge may be a quick or a tedious process requiring considerable processing resources. The knowledge generated must therefore be considered an organizational asset. Knowledge generated within a portal environment or organization, can normally be considered to be of an operational nature. This would follow simply from considering that the use of information technology tools is mostly made in relation to operational matters rather than strategic matters. This is evident, for example through consideration of the kinds of knowledge support systems available to emergent farmers. (Turban, Aronson \& Liang, 2005) In the context of an organization, the users of a portal i.e. CoP can facilitate innovation by turning tacit knowledge into explicit knowledge through externalizing and sharing it with others.

Tacit knowledge is a main resource for new knowledge creation and continuous innovation. "Innovation can be described as the pursuit of an individual's idea through the gradual enlargement of organizational involvement” (Numprasertchai \& Igel, 2005).

As new knowledge is generated, the knowledge base of the organization embedded in the KF grows. Hall and Paradice (2004) explained that organizational learning (problem solving) is an important aspect of organizational growth and success. Unfortunately, the improvements in technology that allow for increases in information acquisition and sharing are also contributing to difficulties in managing the influx of information and therefore may negatively impact the propensity to learn (solve problems). Bollinger et al. (as cited by Numprasertchai \& Igel, 2005) defined knowledge management (KM) as the management of information to support productivity and efficiency through the steering of strategy, identifying explicit knowledge and translating it into tacit knowledge, and explicating tacit knowledge that resides in processes, people, products and services.

Knowledge management practices (KMPs) are specific routines that shape the knowledge base of the firm and make it accessible in the innovation process. Substantial innovations are effected through investment into new knowledge by organizations. The success of organizations depends largely on how effectively and efficiently they can perform processes, such as the identification, acquisition, development, utilization, transfer, and validation of knowledge (Numprasertchai \& Igel, 2005). The same principles for the KMP as applicable in organizations, also apply to Living Lab Environments.

\section{Knowledge Support, Need and Definition}

In order to provide a better clarity of the activities relating to the knowledge factory we need to provide our definition of knowledge support in a LL environment. We define knowledge support as an activity-oriented process aiding knowledge creation, facilitation, sharing, codification and application for its intended user group. 
Without proper and sound knowledge support services, neither the KF nor the PF would be able to function successfully. The SF provides the service infrastructure and resources prospective innovators, infopreneurs and entrepreneurs need to create innovative LL intended support products.

\section{Service Factory - Knowledge Support Services}

The PF, SF, and KF are interconnected by rendering various services and facilitating the actions and activities of the LL CoP. The PF involves various activities related to the creation of new products which are presented as services.

The knowledge factory involves various research activities to aid in the description testing and design of new products. The services provided by the SF are accessible to all users of the LL in each of the various factories. In some instances, cloud computing services can be utilized to help provide the necessary tools needed by members of a Living Lab to reach their desired objectives.

What is known as software as a service (SaaS), will allow users to have access to various kinds of software applications that they need to complete their assigned tasks. This software will be accessible to them without the need to install it on their local machines. This plays an important role as it lets the user/member focus on the core purpose of being part of the Living Lab instead of worrying about installing and updating the software they need to perform their tasks. As an example, through the use of infrastructure as a service (IaaS) users can upload all their documents to an external storage server. Users do not need to have the storage space on their local machines, and this will help protect all the important documents as there will be no risk on the users' side of losing them, as they are not kept on their local machine. These documents can then be available to all members of the Living Lab who need them, at any time. They can be updated as needed. This will effectively create a shared repository of knowledge for the members of the Living Lab concerned. Tags, and RDFs can be used to classify the documents as they are stored, which will in turn speed up the process of locating the relevant information needed by individual members.

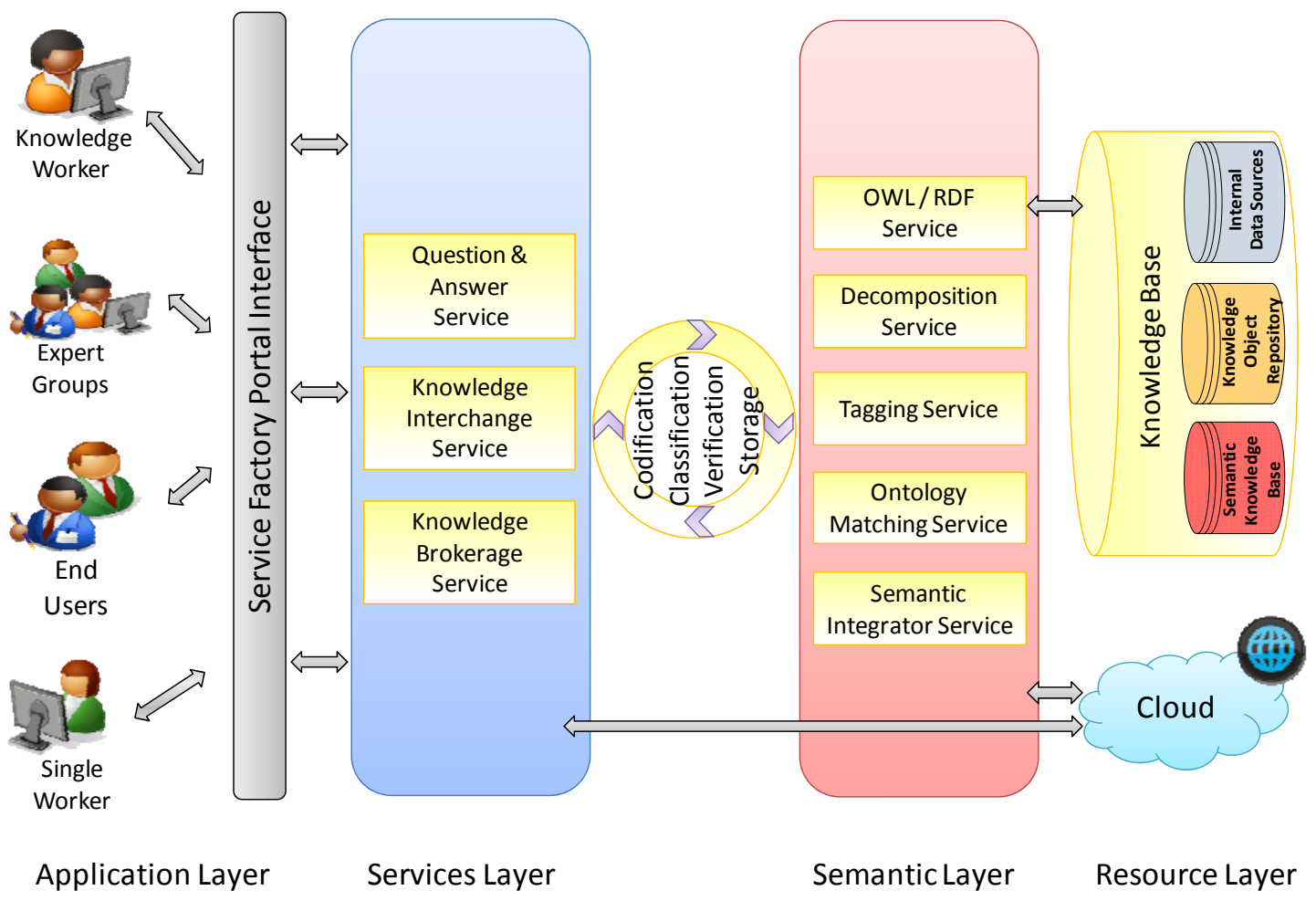

Figure 6 - Knowledge support services framework 
Figure 6, constructed by the researchers depicts some of the services to be rendered to the various users of the LL via the SF interface. It is based on a framework which presents various services using a layered approach. The figure also highlights the position of the various KF systems, and depicts the, KM activities as part of the services layer.

The application layer provides the interface for the access of the different users to the various tools and the LL environment.

The services layer presents the various subsystems, as single or embedded tools to allow learning, and knowledge interchange and knowledge sharing, in various formats. Some activities which could be provided by the utilization of web services include knowledge sharing and clustering, service generation, access provision to smart tools, automatic tracking and tracing of knowledge objects, mobile support, and expert interlinking. These services incorporate a -

1) question and answer service (QAS) which allows users to post questions and obtain answers. The questions as well as the responses are semantically tagged to provide inference services for future questions posted, which will speed-up the knowledge acquisition processes;

2) knowledge interchange (KI) service, which supports the sharing of information among people (online collaboration, i.e. question and answer postings) or through doing research e.g. grounded theory;

3) knowledge brokerage (EKB) service using a reverse auction process; and

4) semantic tagging and classification service, which forms part of the semantic layer, to aid in the understanding of research notes, of both current and future knowledge related documents.

The semantic layer provides the technical functionality and embedded process logic of the knowledge support, QAS and KI activities.

A knowledge object (KO) is described by a simple knowledge ontology which is written to the KOR. The repository stores amongst others metadata of stored artifacts in an external data warehouse. In applicable instances metadata is generated using the METS schema which is a standard for encoding descriptive, administrative, and structural metadata. (METS: 2012). Additional web sources are also gathered with semantic processes from the Web itself. This may include links to other Web 2.0 sites and the extraction of other possible and potential KO metadata. The semantic extrapolation process generates tags which are compared with existing metadata, using semantic pattern clustering in the semantic knowledge repository, which matches existing classes, relations, axioms, functions and instances of prior searches and results. The KOR contains metadata descriptions of KOs applicable to the current LL domain, and the semantic knowledge repository (SKR) references semantic knowledge from external domains.

Figure 7 presents some examples of KOs within an LL environment. It highlights the fact that KOs may take on different forms and that Web 2.0 sources e.g. YouTube and Facebook postings are ideally suited for the purpose of inherent knowledge sharing as well. 


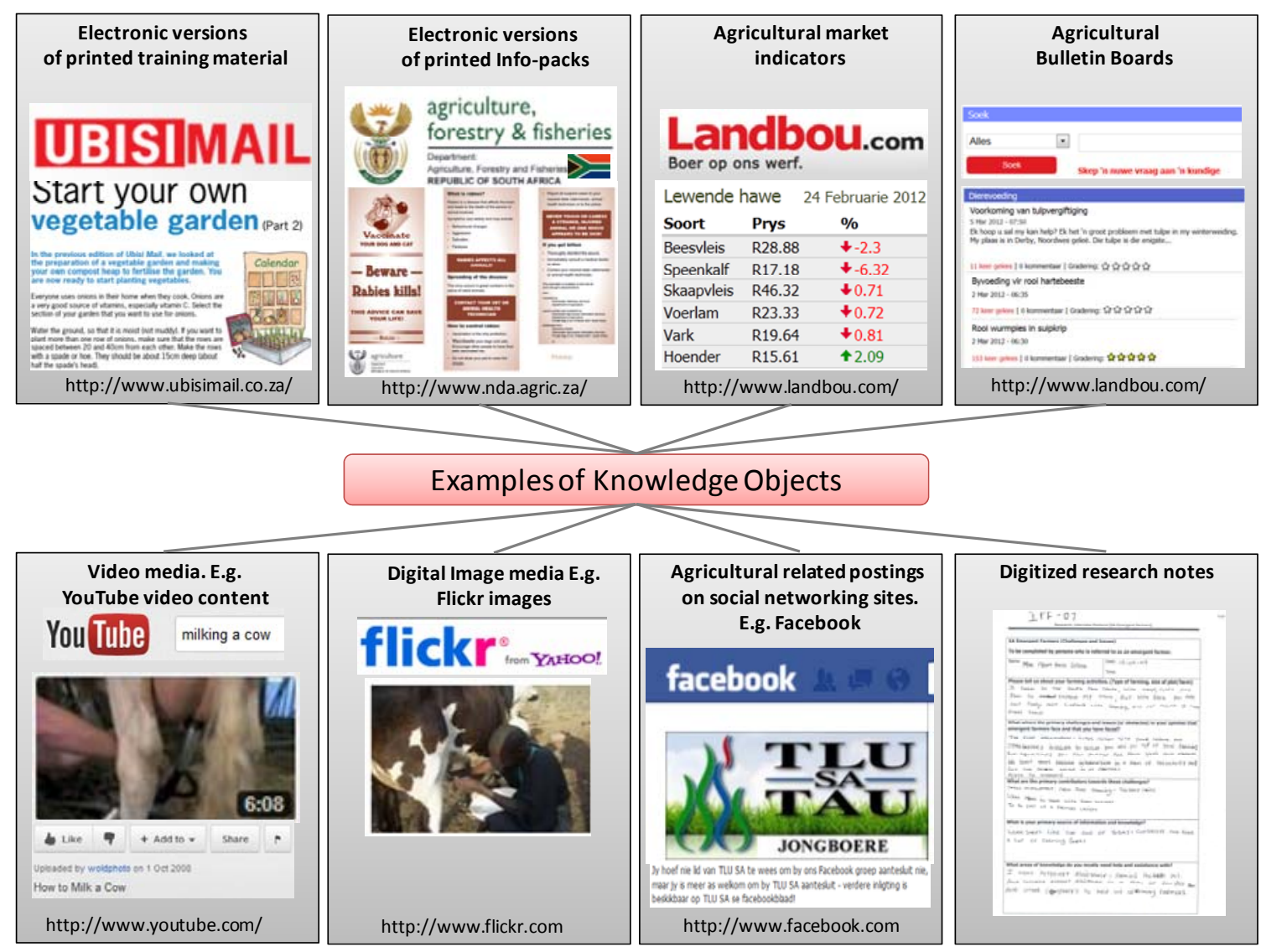

Figure 7 - Examples of KO's in a LL environment

Another important consideration is that KOs could also be in the form of a web service or standard software service, where information is generated through the application of standard business logic. Figure 7 highlights the fact that such a service could include a market price indicator, which would aid farmers and extension officers in their decision making processes. The web service/semantic integrator incorporates web services bus incorporating WSDL and OWLs for the retrieval and discovery of possible data sources and other services, which is not part of the current SKR. The data sources could be from external web content, as well as external domain knowledge bases. The results retrieved from external sources, as part of the knowledge seeking process is then evaluated as part of the research processes by various knowledge officers. The subsequent new knowledge or discoveries are tagged, semantically described and stored as part of the KOR for future use.

\section{Question and Answer, Activity and Services}

We believe that asking questions are the first process in the creation of new information and the subsequent generation of new knowledge. As illustrated in Figure 8, questions facilitate learning which in turn could lead to innovation. The question and answer service (QAS) performs the main functionality of the knowledge support services framework. This service allows users to obtain knowledge through asking and posting questions pertaining to the applicable domain. In brief, the internal sources of data within the portal environment are searched and the results retrieved. The internal sources could be from the portal's internal knowledge base which comprise of the internal LL data sources or the knowledge object repository. When no sufficient information is found, searches and requests to external sources can be made via intelligent search engines such as Google, or Ask. For a last option the user may invoke the help of experts or initialize the 
Knowledge Bidding Service which is described later. The responses from internal sources would be fast, whereas responses from experts and other sources could be slower and cost more.

Throughout the process of dialogue with the user, they would be of cardinal importance to ensure participation and collaboration in the portal.
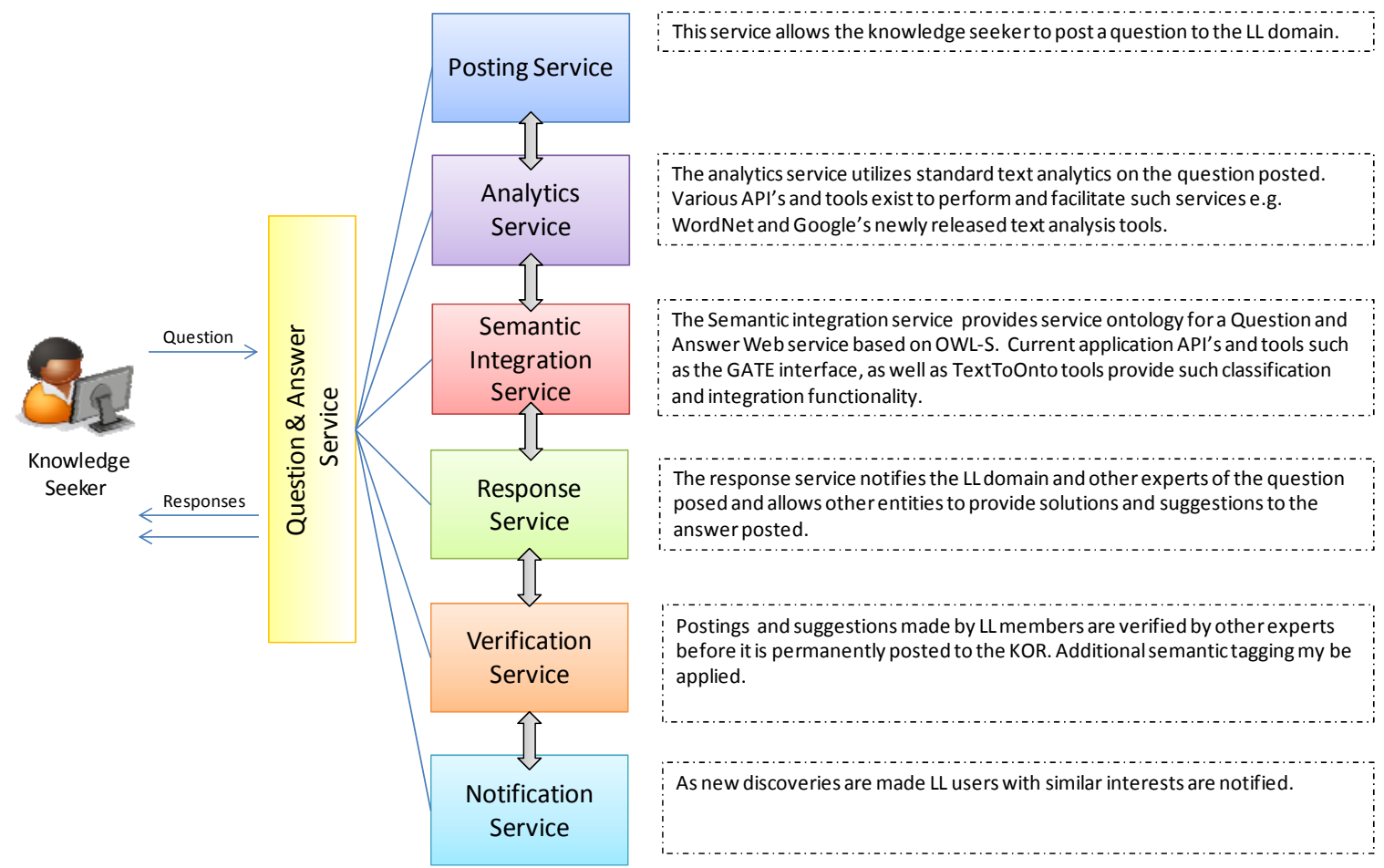

Figure 8 - Question and answer services

The question domain classification process involves a stepwise process flow, where questions that are posted via the question and answer interface as well as the KI are processed and disseminated.

In brief, the semantic processes as depicted in the semantic integration service are as follows: A posted question or request are dissected and broken down into common sentence units, such as verbs, adjectives and nouns. The text mining service utilizes the sentence parts and performs an initial matching activity with prior questions that were stored within the questions and answer repository. Similarities and AI matching methods are applied and matching result-sets from the question and answer repository are returned. The returned result-set and original question is then further analyzed by utilizing natural language processing tools and services.

\section{Knowledge Interchange, Activities and Services}

As depicted in Figure 9, the KI activities and processes closely correlate with standard knowledge management practices and processes as well as knowledge sharing. KI is seen as the process where knowledge from various sources e.g. other users, experts and the semantic web are classified, verified and stored in a data store such as a data mart or knowledge object repository. In other words: Knowledge interchange activities refer to services provided by the portal to facilitate the exchange of relevant information to groups within the portal with the same interest. The knowledge and information generated will then be available for future retrieval to aid in the user's or CoP problem solving needs. 

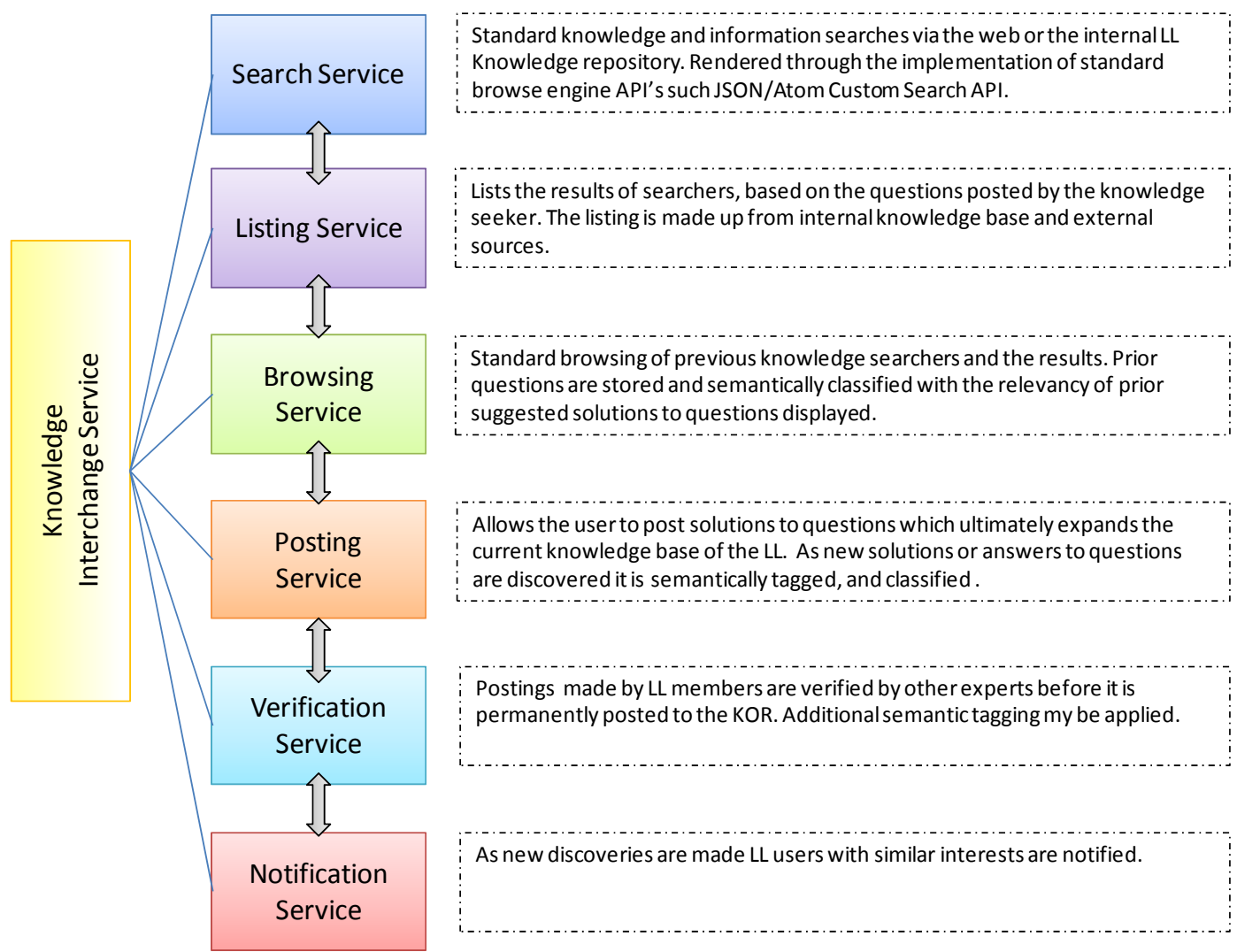

Figure 9 - Knowledge Interchange Services

For example:

- When a new type of pest control substance has been developed for a specific crop, all the applicable farmers within the portal group, which has an interest in that crop, could be notified. It would be irrelevant to send the information to a farmer concerned with meat production,

- If a farmer has found a solution to a specific problem, that solution could be shared with all other members with the same interests.

The KI activities could be facilitated by the creation and implementation of the following services, some of which could be facilitated by implementing standard APIs. The KI services aid the activities of the exchange of information and knowledge from the various users of the LL. The information and knowledge exchanged are passed though the various KM processes. This activity is done on a voluntary basis, with built in controls to ensure data verification, codification and storage for future retrieval. This activity should be based on the codification strategy as supplied by Ruuska and Vartiainen (2005).

\section{Characteristics of the $\mathrm{KI}$ activity}

The implementation of the KI activity as a service within the LL will ensure that the following distinct characteristics would be notable of the LL knowledge support environment:

1. Questions would form the basis for knowledge discovery.

2. Community members should be able to publish and manage their own content. 
3. A reusable knowledge repository would be created and maintained with constant user involvement. The knowledge repository could be in the form of a knowledge base or a digital semantic knowledge object repository.

4. The KI activity would make the LL a "living system", because of the need for continuous interaction between the various community members.

\section{Expert Knowledge Brokerage (EKB) Activities and Services}

Sometimes within LLs, answers to questions will not be obtainable through standard knowledge searches or through the KI activities as described in the previous section. This will occasionally necessitate the LL members to initiate a process where knowledge is acquired through purchase.

The proposed expert knowledge brokerage service will enable this activity. We propose a reverse auction service where various experts may bid to supply knowledge for specific user's knowledge requirements.

Figure 10 constructed by the researchers depict the various knowledge brokerage services, as well as how the various parties interact.

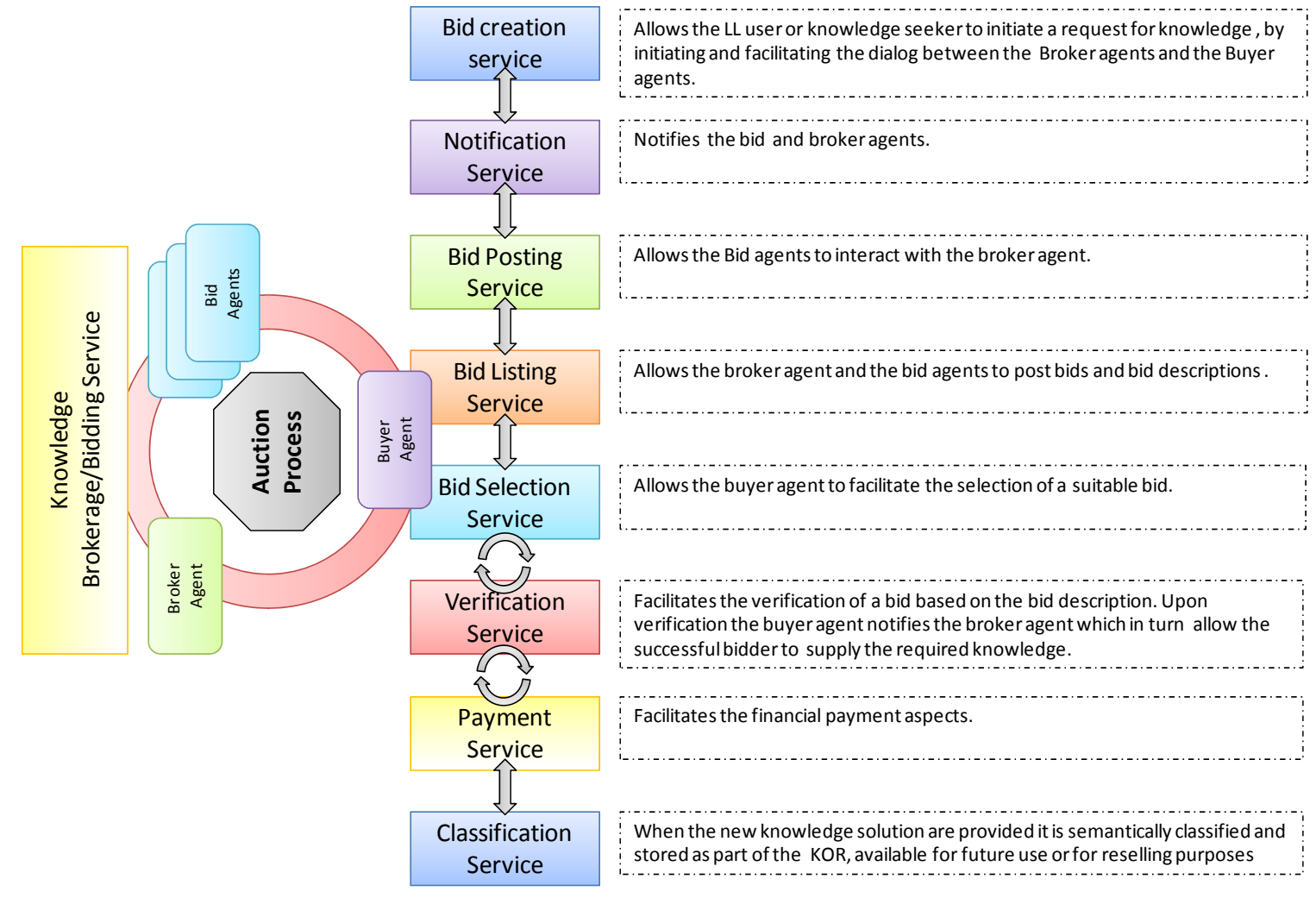

Figure 10 - Knowledge Brokerage Services

The reverse auction process can be considered as a revised auction process. In terms of this process the role of the bidder and owner is re-designed through a broker and/or software. Knowledge flows in an auction environment facilitate and coordinate multiple, geographically dispersed knowledge owners (Yoo, Suh \& Kim, 2007). According to Murzyn (2002), the three role players in a reverse auction are the buyer, the suppliers, and the intermediary. The buyer sets the auction rules, and determines which suppliers will be invited to participate. The buyer weighs the buying criteria in addition to purchase price. Suppliers have a large effect on auction dynamics. Suppliers use factors such as bidding strategies, knowledge of the market, and prior experience with 
auctions to their advantage. Usually the intermediary's role is the least understood as it varies from auction to auction. One role may be to only host auction software and to provide support for the auction (e.g., a call center), for both the buyer and suppliers. But the most significant role of an intermediary lies in the work done before and after an auction. The buyer pays the intermediary, which helps the buyer before and after the auction by making use of previous knowledge gathered from auctions.

Terminology used by contributors and bidders of knowledge differ, making automation troublesome. The solution to this is to have an automated knowledge map generation technique. The software should be generated and operated by the broker. Such software has to ensure high quality and have a low error tolerance. Through a broker dealing with auctions, this software with known terminologies should already be in place, saving companies time and money to set it up from scratch. Appointing a broker to leverage the amount it would have cost in-house to develop such a system from scratch is recommended by Venkatsubramanyan (2010).

In the case of a knowledge reverse auction (RA), experts will bid against each other to supply a solution for a specific user's knowledge need. The RA process could also generate an income for the portal since a levy could be charged to each of the agents as well as the experts providing a knowledge support service.

Benefits for knowledge owners, i.e., LL CoP, in a reversed auction are, among others, 1) a chance to promote their knowledge on interesting fields, and 2) getting publicity due to their knowledge presentation. The other side of the coin includes benefits for bidders such as, 1) brand-new, innovative and intelligent knowledge which ensure competitiveness in the market of similar companies, 2) the quality of knowledge is guaranteed as an expert panel evaluates it, and 3) networking with other innovative parties becomes possible, which can lead to potential future partnerships (Lienemann, 2010).

We believe that a reverse auction process implemented via brokers is an ideal process for the acquisition of knowledge and solutions which would otherwise not be available to the LL CoP.

\section{Conclusion}

As technology continues to evolve, one wave of technology will impact other technologies. Through the evolution of the Web, which already gave birth to Web 2.0 and the Semantic Web, tools were created that have an enormous impact on how people and users conduct their business and approach learning and dissemination of knowledge.

It is clear from the above discussion, that knowledge support activities and services can play an important role in promoting the creation and sharing of knowledge within a Living Lab setting. These technologies have specific uses that can be combined into a single approach to assist members within the Living Lab with their knowledge creation and knowledge sharing activities. Additionally they also promote collaboration between members and allow for constant interaction, despite their geographical locations, thereby effectively extending the pool of individuals who can form part of the actual Living Lab. The benefits as listed below, would be immense as individuals from diverse backgrounds can be part of the initiative in that it -

1. allows for the integration of various knowledge domains within the LL;

2. creats a dynamic knowledge directory;

3. motivates and encourages communication (e.g. sharing of ideas), between different users of different knowledge levels;

4. enhances collaboration; 
5. creates opportunities for and support learning amongst the CoP members;

6. acts as a motivator for the users of the portal, because the KSP will aid in the problem solving and knowledge discovery processes of its members;

7. makes the LL more "sticky", which will contribute towards the attraction of more members; and

8. enables the generation of funds for the LL by means of commissions that could be charged to experts providing knowledge services.

We strongly believe that the establishment of Living Labs within CoPs could really benefit not only its intended users and their proximate communities, but also the broader user domain. For instance, within a rural agricultural community, an innovative solution for a specific problem could be discovered. With the proper knowledge and skills being available, this solution could be brought to the attention of other stakeholders and benefit the community. This not only promotes and enhances an entrepreneurial drive for the community but it also aids in stimulating a culture of creativity and innovation.

\section{References}

Arshad, J., Townend, P., \& Xu, J. (2011). A novel intrusion severity analysis approach for clouds. Future Generation Computer Systems (0).

Bergvall-Kåreborn, B., Holst, M., \& Ståhlbröst, A. (2009). Concept design with a living lab approach. Proceedings of the 42nd Hawaii International Conference on System Sciences.

Bergvall-Kåreborn, B., \& Ståhlbröst, A. (2011). Living lab: An open and user-centric design approach. Hershey, Pa: IGI Global.

Bergvall-Kåreborn, B., \& Ihlström, C., \& Ståhlbröst, A., \& Svensson, J,. (2009). A milieu for innovation Defining living labs. 2nd ISPIM Symposium, New York, 6-9 December, 2009. Retrieved 29 February, 2012, from http://pure.Itu.se/portal/files/3517934/19706123_Paper.pdf

Buitendag, A. A. K. (2011). Living labs for knowledge support. D-Tech dissertation, work in progress.

Coetzee, H., \& du Toit, I. M. (2011). Case study report: Living labs in Southern Africa. Retrieved 1 January, 2012, from http://www.llisa.net

Chen, Y. T. (2011). Formulate service innovation in accordance with a living-lab based service engineering architecture. 2011 International Joint Conference on Service Sciences.

Cilliers, J., (2008). In search of meaning between Ubuntu and Into: Perspectives on preaching in postapartheid South Africa. Retrieved 31 January, 2012 from http://academic.sun.ac.za/tsv/Profiles/Profile_documents/Johan_Cilliers_IN_SEARCH_OF_MEANIN G_BETWEEN_UBUNTU_AND_INTO.pdf

CoreLabs/ENoLL. (2007). European network of living labs. Accessed on 20/07/2007 from www.corelabs.eu

Cunningham, P., Herselman, M., \& Cunningham, M. (2011). Supporting the evolution of sustainable living labs and living lab networks in Africa. Version 1.8, 09 November, 2011. Ireland: IIMC International Information Management Corporation, Ltd. ISBN: 978-1-905824-28-1.

Dorey, P. G., \& Leite, A. (2011). Commentary: Cloud computing - A security problem or solution? Information Security Technical Report(0).

Følstad, A. (2008). Living labs for innovation and development of information and communication technology: A literature review. The Electronic Journal for Virtual Organizations and Networks, 10 (Special Issue on Living Labs), August 2008. 
Free State Department of Agriculture. (2010). Extension services. Retrieved 20 April 2009, from, www.fs.agric.za/ext ension Accessed on 20/04/2009

Greenfield, J., \& Short, K. (2003). Software factories Assembling applications with patterns, models, frameworks and tools. OOPSLA'03, October 26-30, 2003, Anaheim, California, USA.ACM 1-58113751-6/03/0010.

Hall, D. J., \& Paradice, D. (2004). Philosophical foundations for a learning-oriented knowledge management system for decision support. Retrieved 20 April 2007 from http://www.sciencedirect.com

Kusiak, A. (2007). Innovation: The living laboratory perspective. Computer-Aided Design \& Applications, 4(6), 863-876. Retrieved 4 April, 2009 from www.icaen.uiowa.edu/ ankusiak/Journalpapers/CAD_07.pdf

Lenz, G. (2008). An introduction to software factories. Retrieved 3 March 2009, from http://architects.dzone.com/articles/an-introduction-software-facto

Leon, M. P. D., Eriksson, M., Balasubramaniam, S. \& Donnelly, W. (2006). Creating a distributed mobile networking testbed environment - through the Living Labs approach. Retrieved 9 June, 2011 from http://repository.wit.ie/645/

Lienemann, K. (2010). HighTech Europe, Knowledge auction on food packaging innovations. Knowledge Auction Guidelines. Retrieved 26 April, 2011 from www.knowledgeauction.eu

lltoolbox (2009). Living lab toolbox. Retrieved 2 February, 2012 from http://www.lltoolbox.eu/

LLiSA. (2011). Living labs South Africa. Retrieved 12 March, 2011 from http://lisa.meraka.org.za/index.php/Living_Labs_in_Southern_Africa

METS. (2012). Metadata coding and transmission standard. Retrieved 6 March, 2012 from http://www.loc.gov/standards/mets

Murzyn, P. (2002). The strategic source. Reverse auctions: The Roles of the Players. B2eMarkets' archived article.

Nabil, S. (2010). Cloud computing for education: A new dawn? International Journal of Information Management, 30(2), 109-116.

NDA - National Department of Agriculture - South Africa. (2006). Farmers defined. Retrieved 14 January, 2009 from www.nda.agric.za/docs/Cropsestimates/DEFINITION\%20COMM\%20AND\%20SUBSISTENCE

Numprasertchai, S., \& Igel, B. (2005). Managing knowledge through collaboration: multiple case studies of managing research in university laboratories in Thailand. Retrieved 9 April, 2008 from http://www.sciencedirect.com

Openlivinglabs.eu. (2012). European Network of living labs (ENoLL). Retrieved 31 January, 2012 from http://www.openlivinglabs.eu/

Purdy, D. (2002). Microsoft Corporation - Exploring the factory design pattern. Retrieved 1 February, 2012 from http://msdn.microsoft.com/en-us/library/ee817667.aspx

RLabs.org. (2012). Products and services. Retrieved 31 January, 2012 from http://www.rlabs.org/what-wedo/products-and-services/

Ruuska, I., \& Vartiainen, M. (2005). Characteristics of knowledge sharing communities in project organizations. Retrieved 31 January, 2012 from http://www.sciencedirect.com

Schuurman, D., Moor, K. D., \& Marez, L. D. (2010). Investigating user typologies and their relevance within a living lab- research approach for ICT-innovation. Proceedings of the 43rd Hawaii International Conference on System Sciences.

Thompson, W. J. J., Buitendag, A. A. K., \& van der Walt. J. S. (2011). The agile farmer: A beef farmer case study, in Southern Africa. EFITA/WCCA 2011 Joint Conference. Prague, Czech Republic. 1114th July 
Tuncay, E. (2010). Effective use of cloud computing in educational institutions. Procedia - Social and Behavioral Sciences, 2(2), 938-942.

Turban, E., Aronson, J. E., \& Liang, T. (2005). Decision support systems and intelligent systems (7th ed.). USA: Prentice Hall.

Valderrama, R. P., Cruz, A. C., \& Valderrama, I. P. (2011). An approach toward a software factory for the Development of Educational Materials under the paradigm of WBE. Interdisciplinary Journal of ELearning and Learning Objects, 7, 55-67. Retrieved from http://www.ijello.org/Volume7/IJELLOv7p055-067Valderrama738.pdf

Van Der Walt, J. S., Buitendag, A. A. K., Jansen Van Vuuren, J. C., \& Zaaiman, J. J. (2009). Living lab as a collaborative innovation environment. Issues in Informing Science and Information Technology (IISIT), 6, 421-436.

Venkatsubramanyan, S. (2010). Streamlining knowledge map construction for an online auction house using automatic term filtering. International Journal of Applied Logistics, 1(4), 64-79.

Yoo, K., Suh. E., \& Kim, K. Y. (2007). Knowledge flow-based business process redesign: applying a knowledge map to redesign a business process. Journal of Knowledge Management. 11(3) 104-125.

\section{Biographies}

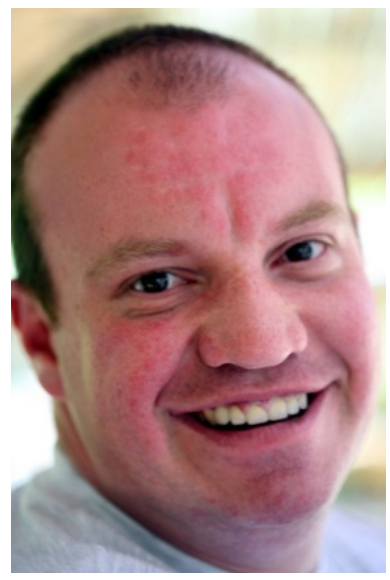

Bertie Buitendag is currently enrolled for his D-Tech in Enterprise Application Development at TUT under the supervision of Prof JS van der Walt. His core research area includes ICT Knowledge support for emergent farmers and Living Labs. Other areas of interest include the: Semantic Web, (WEB 3.0) and WEB 2.0, and ICT's for community upliftment.

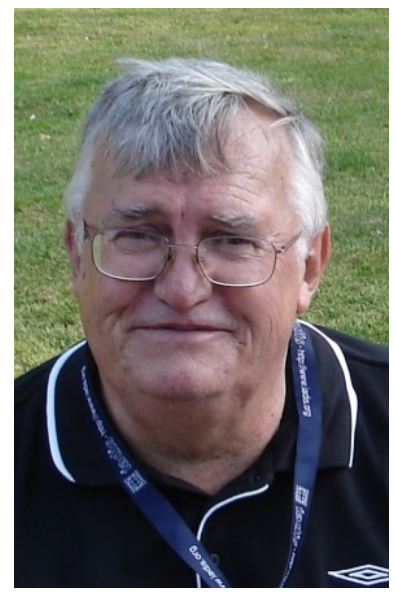

Prof. Jacobus (Potjie) van der Walt has been intensively involved into ICT research over the past 27 years at the Tshwane University of Technology (TUT). His core research interests currently pertain into the study of emergent community-oriented ICT support, with specific reference to portal based applications for emergent farmers. He has successfully supervised numerous post graduate students. He was also one of the first academia in South Africa to publish a paper regarding community oriented Living Labs. He also started the Soshanguve LL initiative. 


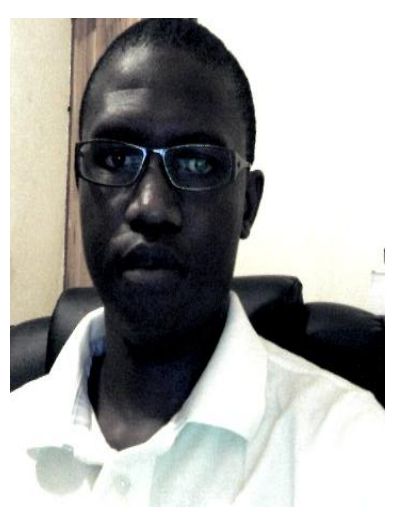

Tumelo Malebane is currently enrolled for his M-Tech in Enterprise Application Development at TUT. His core research area includes Cloud Computing and the application of Living Labs in educational environments. Other areas of interest include the: Artificial Neural Networks and Machine Learning.

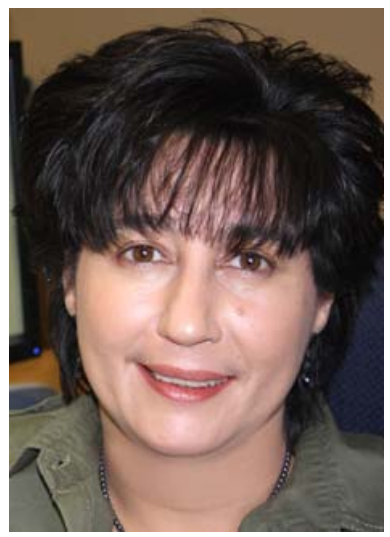

Lizette de Jager is currently enrolled for her M-Tech at TUT, Faculty ICT. Prof JS van der Walt is her study leader and supervisor. The main area of her research is to explore the use of Knowledge Management, within a Living Lab environment, in Universities by investigating and comparing the maturity level of KM. The Living Lab environment is collaborative and therefore ideal for KM. 